\title{
Smac mimetic-derived augmentation of chemotherapeutic response in experimental pancreatic cancer
}

\author{
Niranjan Awasthi ${ }^{1,3}$, Amanda Kirane ${ }^{1,3}$, Margaret A Schwarz ${ }^{2}$, Jason E Toombs ${ }^{1,3}$, Rolf A Brekken ${ }^{1,3,4}$, \\ Roderich E Schwarz ${ }^{1,3^{*}}$
}

\begin{abstract}
Background: Pancreatic ductal adenocarcinoma (PDAC) is highly resistant to conventional chemotherapy, in part due to the overexpression of inhibitors of apoptosis proteins (IAPs). Smac is an endogenous IAP-antagonist, which renders synthetic Smac mimetics attractive anticancer agents. We evaluated the benefits of combining a Smac mimetic, JP1201 (JP), with conventional chemotherapy agents used for PDAC management.

Methods: Cell viability assays and protein expression analysis were performed using WST-1 reagent and Western blotting, respectively. Apoptosis was detected by annexin V/propidium iodide staining. In vivo tumor growth and survival studies were performed in murine PDAC xenografts.

Results: JP and gemcitabine (Gem) inhibited PDAC cell proliferation with additive effects in combination. The percentage of early apoptotic cells in controls, JP, Gem and JP + Gem was 17\%, 26\%, 26\% and 38\%, respectively. JP-induced apoptosis was accompanied by PARP-1 cleavage. Similar additive anti-proliferative effects were seen for combinations of JP with doxorubicin (Dox) and docetaxel (DT). The JP + Gem combination caused a 30\% decrease in tumor size in vivo compared to controls. Median animal survival was improved significantly in mice treated with $J P+$ Gem (38 d) compared to controls (22 d), JP (28 d) or Gem (32 d) $(p=0.01)$. Animal survival was also improved with JP + DT treatment (32 d) compared to controls (16 d), JP (21 d) or DT alone (27 d).
\end{abstract}

Conclusions: These results warrant further exploration of strategies that promote chemotherapy-induced apoptosis of tumors and highlight the potential of Smac mimetics in clinical PDAC therapy.

\section{Background}

Pancreatic ductal adenocarcinoma (PDAC) is the fourth leading cause of cancer-related deaths in the United States. Prognosis of PDAC patients is very poor mostly due to the late diagnosis, aggressive nature of disease and an unusually high resistance to chemotherapy and radiation [1-3]. Despite advancements in diagnostic and surgical procedures and treatments, the overall 5-year survival remains less than 5\% [1]. Surgical resection remains the only option for long-term survival of patients. However, locally extended and metastatic disease limits the use of this procedure to only about $10 \%$

\footnotetext{
* Correspondence: Roderich.Schwarz@utsouthwestern.edu 'Division of Surgical Oncology, Department of Surgery, The University of Texas Southwestern Medical Center Dallas, TX 75390, USA Full list of author information is available at the end of the article
}

of patients [4]. Therefore, the majority of pancreatic cancer patients are treated with systemic therapies. Gemcitabine (Gem), a fluorinated pyrimidine antagonist, is currently the most active single agent for locally advanced, non-operable and metastatic PDAC. However, Gem is only effective in a subset of patients, and improvements in overall survival remain considerably modest [5]. Several other cytotoxic and chemotherapy agents such as cisplatin, fluorouracil, erlotinib, oxaliplatin, docetaxel and irinotecan have been tested as second-line chemotherapy or in combination with Gem for PDAC. However, most of these studies have failed to show any significant improvement in overall patient survival compared to single agent Gem [6-12]. Therefore, there is an urgent need for the development of therapeutic strategies that target novel mechanisms, and are

\section{Biomed Central}

(c) 2011 Awasthi et al; licensee BioMed Central Ltd. This is an Open Access article distributed under the terms of the Creative Commons Attribution License (http://creativecommons.org/licenses/by/2.0), which permits unrestricted use, distribution, and reproduction in any medium, provided the original work is properly cited. 
either effective alone or enhance the activity of standard agents.

Many cancer cells possess apoptotic dysfunction that correlates with tumor aggressiveness and resistance to conventional chemotherapy [13]. Various antiapoptotic proteins including inhibitors of apoptosis (IAPs) have been linked to cancer cell escape from apoptosis $[14,15]$. A high percentage of pancreatic cancer cell lines and tumors express IAPs, including X-linked IAP (XIAP) [16-18] at elevated levels compared to normal tissue. Manipulating IAPs has been identified as a promising approach for cancer treatment. Second-mitochondria derived activator of caspase (Smac) is a mitochondrial protein released into the cytosol upon apoptosis induction or mitochondrial dysfunction. Smac inhibits IAPs and promotes caspase activation and apoptosis [19,20]. Recently, small-molecule mimetics of Smac have been developed that can promote cancer cell apoptosis either alone or in combination with other proapoptotic agents $[16,21,22]$. In fact the Smac mimetic JP1201 (JP) has recently been shown to augment the Gem response in PDAC MIA PaCa-2 cells [23].

In the present study we evaluated the effect of JP on the in vitro and in vivo therapeutic efficacy of various cytotoxic chemotherapy agents in an effort to provide a more effective antitumor strategy for PDAC.

\section{Methods}

\section{Cell culture and reagents}

Human PDAC cell lines, AsPC-1, Panc-1, BxPC-3 and MIA PaCa-2 were obtained from the American Type Culture Collection (ATCC, Rockville, MD). Cell lines were cultured in RPMI 1640 medium (Sigma Chemical Co., St. Louis, MO) supplemented with $10 \%$ fetal bovine serum (FBS) and $100 \mathrm{U} / \mathrm{ml}$ penicillin/streptomycin solution (Sigma) at $37^{\circ} \mathrm{C}$ in a humidified $5 \% \mathrm{CO}_{2}$ atmosphere. JP was obtained from Joyant Pharmaceuticals (Dallas, TX), Gem was purchased from Eli Lilly Corporations (Indianapolis, IN), doxorubicin (Dox) was purchased from Ben Venue Laboratories (Bedford, $\mathrm{OH}$ ) and docetaxel (DT) was purchased from Sanofi-aventis (Bridgewater, NJ).

\section{Cell viability assay}

In vitro cell viability of PDAC cell lines was evaluated by using the colorimetric WST-1 reagent (Roche Diagnostics, Indianapolis, IN) as described earlier [24]. The assay is based on the ability of viable cells to cleave the sulfonated tetrazolium salt WST-1 (4-[3-(4-iodophenyl)2-(4-nitrophenyl)-2H-5-tetrazolio]-1,3-benzene disulfonate) by mitochondrial dehydrogenases. Briefly, PDAC cells $(4,000$ cells per well) were plated in a 96-well plate in regular growth medium and after 16 hours the medium was replaced with $2 \%$ FBS containing medium.
After 5 hours incubation the cells were treated with JP, Gem, Dox or DT, either alone or in combination. After additional incubation of 72 hours, $10 \mu \mathrm{lWST}-1$ reagent was added in each well followed by incubation for 2 hours. The absorbance at $450 \mathrm{~nm}$ was measured using a microplate reader.

\section{Western blot analysis}

A monolayer of cells at 75 to $80 \%$ confluence was placed in 2\% FBS containing medium for at least 5 hour before treatment with JP $(10 \mu \mathrm{M})$, gemcitabine $(10 \mu \mathrm{M})$ for 24 hours. Cells were lysed and equal amounts of total protein were separated by SDS-PAGE and transferred to PVDF membranes (Bio-Rad, Hercules, CA). The membranes were blocked for 1 hour at room temperature with gentle shaking in TBS-T $(10 \mathrm{mM}$ Tris$\mathrm{HCl}(\mathrm{pH} 7.6), 150 \mathrm{mM} \mathrm{NaCl}, 0.05 \%$ Tween 20). The membranes were incubated overnight at $4^{\circ} \mathrm{C}$ with the following antibodies: phospho-JNK, (Santa Cruz Biotechnologies, Santa Cruz, CA), poly (ADP-ribose) polymerase-1 (PARP-1) (Cell Signaling Technology, Beverly, MA), $\alpha$-tubulin or GAPDH (Sigma). The membranes were then incubated with corresponding HRP-conjugated secondary antibodies (Pierce Biotechnologies, Rockford, IL) for 1 hour at room temperature. Specific bands were detected using the enhanced chemiluminescence reagent (ECL, Perkin Elmer Life Sciences, Boston, MA) on autoradiographic film and quantitated by densitometry.

\section{Apoptosis assay by Annexin V-FITC and propidium iodide (PI) staining}

Effect of JP and Gem on AsPC-1 cell apoptosis was detected by using the Annexin V-FITC apoptosis detection kit (BioVision, CA) as per manufacturer's protocol. Briefly, AsPC-1 cells were grown in $10 \%$ serum containing medium up to $80 \%$ confluence, medium was changed to $2 \%$ serum containing medium and incubated for 5 hours and then treated with JP $(10 \mu \mathrm{M})$ and Gem (10 $\mu \mathrm{M})$ for 12 hours. After incubation, cells were trypsinized and suspended in $1 \mathrm{ml}$ of low serum medium. From each cell suspension $2 \times 10^{5}$ cell were centrifuged and re-suspended in $500 \mu \mathrm{l} 1 \mathrm{X}$ binding buffer. In each sample $5 \mu \mathrm{l}$ of Annexin V-FITC and $5 \mu \mathrm{l}$ of PI was added, incubated for 5 minutes in dark and immediately analyzed by flow cytometry (FACS Calibur System, BD Biosciences, Franklin Lakes, NJ). The annexin V - FITC positive and PI-negative cells were considered to be early apoptotic cells.

\section{Animal Studies}

All animal studies were performed in accordance with the Institutional Animal Care and Use Committee at the University of Texas Southwestern Medical Center 
(Dallas, TX). In vivo animal studies were performed using 4-6 weeks old SCID mice purchased from an on campus facility. Tumor growth experiments were performed by orthotopically injecting $1 \times 10^{6}$ Panc- 1 cells. Animals were examined by ultrasound and randomized into treatment groups when tumor size averaged $500 \mathrm{~mm}^{3}$ at approximately 8 weeks after tumor cell injection. Animals were injected intraperitoneally with PBS (control), JP $(6 \mathrm{mg} / \mathrm{kg}$ in $100 \mu \mathrm{l} \mathrm{PBS}$, three times weekly) and Gem $(25 \mathrm{mg} / \mathrm{kg}$ in $100 \mu \mathrm{l}$ PBS, three times weekly), either alone or in combination. Three mice from each treatment group were sacrificed at 24 hours of therapy while the remaining animals in each group received 2 weeks of therapy prior to sacrifice.

Animal survival studies were conducted in an intraperitoneal PDAC tumor model as previously described [25]. Female SCID mice received $0.75 \times 10^{6}$ human AsPC-1 cells intraperitoneally. The animals were randomly grouped ( $\mathrm{n}=6$ to 8 per group) and treated intraperitoneally with PBS (control), JP $(6 \mathrm{mg} / \mathrm{kg}$ in $100 \mu \mathrm{l}$ PBS, twice weekly), Gem (100 mg/kg in $100 \mu \mathrm{l} \mathrm{PBS,}$ twice weekly) and DT (3 mg/kg in $100 \mu \mathrm{l} \mathrm{PBS,} \mathrm{twice}$ weekly), either alone or in combination for 14 days or as maintenance therapy. Animal weight was measured twice weekly and all animals were examined daily for signs of distress or development of jaundice. Moribund mice at risk for distress were euthanized in accordance with the local animal care committee protocol. Subsequently, animals were examined for presence and extent of intra-abdominal tumor.

\section{Statistical analysis}

In vitro cell proliferation assay results are expressed as mean \pm standard deviation. Statistical significance was analyzed by the two-tailed Student's t-test using GraphPad Prism 4 Software (GraphPad Software, San Diego, CA). For in vivo studies, statistical analysis was performed by ANOVA for multiple group comparison and Student's t-test for the individual group comparison. In survival studies, statistical differences were analyzed by nonparametric survival statistics and logrank test. Values of $\mathrm{p}<0.05$ were considered to represent statistically significant group difference.

\section{Results}

Effect of JP and Gem on PDAC cell proliferation

In vitro WST-1 assay was performed to examine the effect of JP and Gem on PDAC cell proliferation. In AsPC-1 cells, JP and Gem significantly inhibited the cell proliferation. After 72 hours of incubation, JP $(1 \mu \mathrm{M})$ and Gem $(500 \mathrm{nM})$ inhibited the AsPC-1 cell proliferation by $31 \%$ and $58 \%$, respectively (Figure 1 ). The combination of JP and Gem had an additive effect on inhibition of AsPC-1 cell proliferation, with an inhibition in cell proliferation of $70 \%$ after 72 hours of incubation (Figure 1). At these concentrations, the inhibition in cell proliferation of other PDAC lines in JP, Gem and JP + Gem groups were 54\%, $10 \%$ and $79 \%$ for Panc- $1 ; 42 \%, 56 \%$ and $77 \%$ for BxPC-3; and 9\%, 43\% and $77 \%$ for MIA $\mathrm{PaCa}-2$, respectively.

\section{Effect of JP and Gem on PDAC apoptosis}

We examined if the inhibition in AsPC-1 cell viability by JP and Gem could in part be due to induction of apoptosis. Annexin V/PI staining assay revealed an increase in early apoptotic cells by JP and Gem treatment that was further increased by combination of these agents (Figure 2A). At $10 \mu \mathrm{M}$ concentration of either agent, the percentage of early apoptotic cells was $17 \%$ in controls, $26 \%$ in JP or Gem, and $38 \%$ in the JP + Gem group. (Figure 2A).

We also measured cleavage of PARP- 1 protein, a caspase-dependent apoptosis-marker protein, after JP and Gem treatment. A significant increase in the expression of cleaved PARP-1 protein was observed after treatment with JP, but not after exposure to Gem (Figure 2B).

\section{Combination effects of JP and doxorubicin or docetaxel on PDAC cell proliferation}

We next evaluated if JP can sensitize other chemotherapeutic agents. In vitro WST-1 assay revealed that JP, Dox and DT inhibited the proliferation of all four PDAC cell lines tested in a dose-dependent manner (Figure 3). Interestingly, the combinations of JP with either doxorubicin or docetaxel had additive effects on inhibition of proliferation of PDAC cell lines (Figure 3). At intermediate concentrations of these agents, inhibition in cell proliferation in AsPC-1 cells in JP $(5 \mu \mathrm{M})$, Dox $(1 \mu \mathrm{M})$, DT $(1 \mu \mathrm{M})$, JP + Dox and JP + DT groups were $40 \%, 39 \%, 48 \%, 73 \%$ and $73 \%$, respectively. Similar additive combination effects of JP with Dox or DT were observed regarding Panc-1, MIA PaCa-2 and BxPC-3 proliferation (Figure 3).

Evaluation of PARP-1 cleavage after JP, Dox and DT treatment by Western blot analysis revealed that Dox and DT had no effect on PARP-1 cleavage, while JP exposure led to a significant increase in PARP-1 cleavage (Figure 4).

\section{In vivo effects of JP addition to gemcitabine and docetaxel}

The antitumor impact of JP, Gem and DT, either alone or in combination, was evaluated in murine PDAC xenografts. In an orthotopic Panc-1 xenograft model, tumor weights were measured at completion of therapy and compared to tumors harvested at 24 hours of therapy (Figure 5). The increase in tumor weight was $87 \%$ in controls, while Gem and JP treatment alone trended 


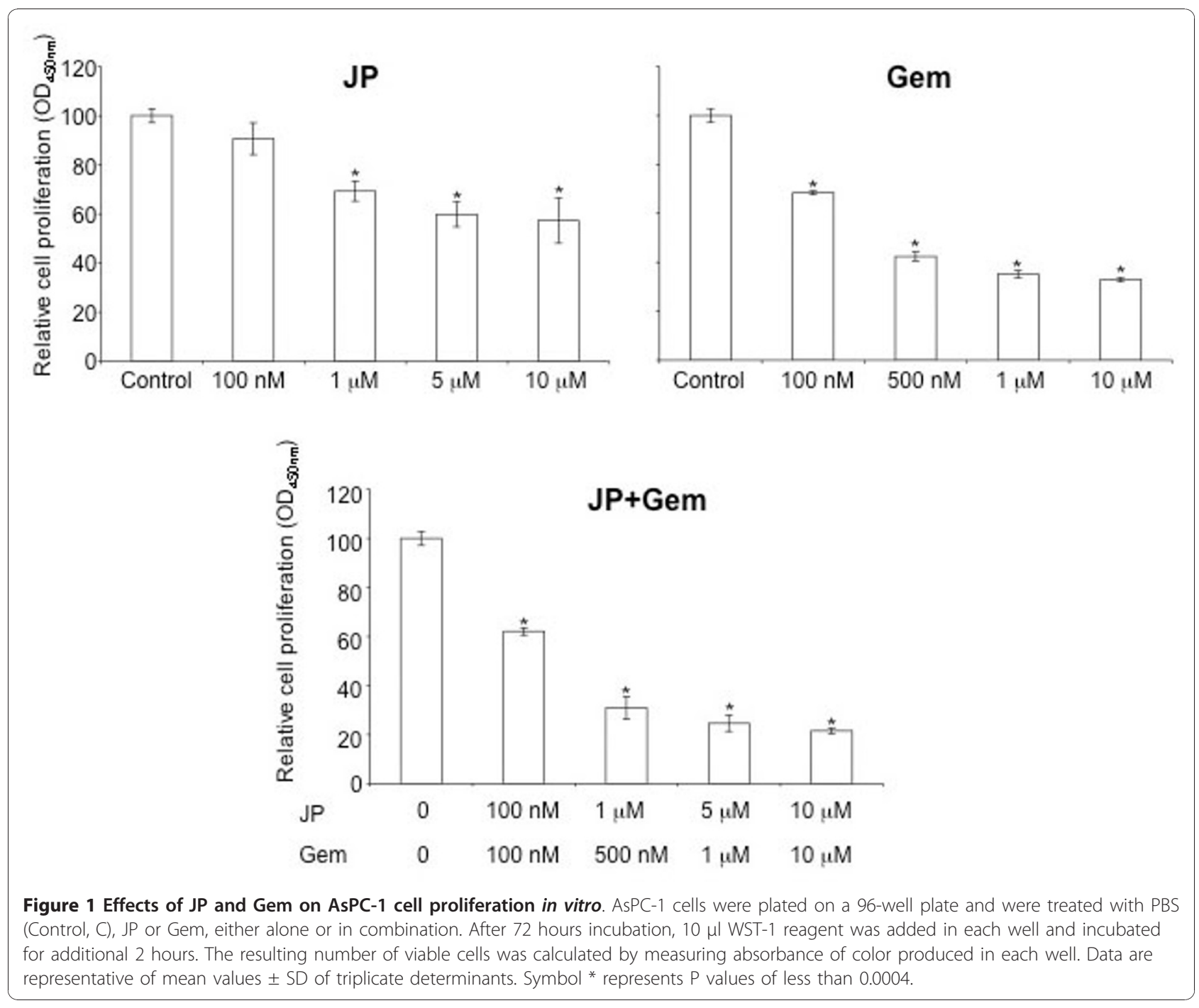

towards decreased tumor growth, albeit not significant. $\mathrm{JP}+$ Gem combination treatment resulted in decreased tumor weight compared to that at treatment start, with a mean reduction of approximately $30 \%(\mathrm{p}<0.05$ verses control) (Figure 5). In survival studies with maintenance therapy, a statistically significant improvement in animal survival was observed in mice treated with the combination of JP + Gem (median: 38 days, $\mathrm{p}=0.01$ ) compared to controls (22 days) or single agent treatment with JP (28 days) or Gem (32 days, $\mathrm{p}=0.02$ ) (Figure 6A). Animal survival was also significantly improved in a 14-day combination treatment with JP + DT (32 days) as compared to controls (16 days) or single agent treatment with JP (21 days) or DT (27 days) (Figure 6B). In addition to survival impact, we also evaluated the treatment effects of JP and DT on inhibition of local tumor growth in subcutaneous AsPC-1 pancreatic cancer xenografts. JP enhanced the DT-mediated local antitumor effects: compared with controls, addition of JP enhanced the inhibition in net tumor growth by DT of $57 \%$ to $91 \%$ in combination $(\mathrm{p}=\mathrm{NS})$, respectively (data not shown).

\section{Discussion}

Resistance to conventional chemotherapy continues to be a challenge in PDAC. Acquired resistance to apoptosis, which is prevalent in PDAC, is a critical pathway that promotes resistance to conventional chemotherapy $[17,18]$. Therefore, targeting apoptosis resistance has emerged as an attractive novel cancer therapeutic strategy $[26,27]$. Small molecules with proapoptotic activity are particularly advantageous, as they are membrane permeable, inhibit antiapoptotic molecules, augment efficacy of current therapeutics and minimize side effects of single agent therapy. Smac mimetics represent a novel class of anticancer drugs that are currently undergoing clinical evaluation [28]. We studied the 


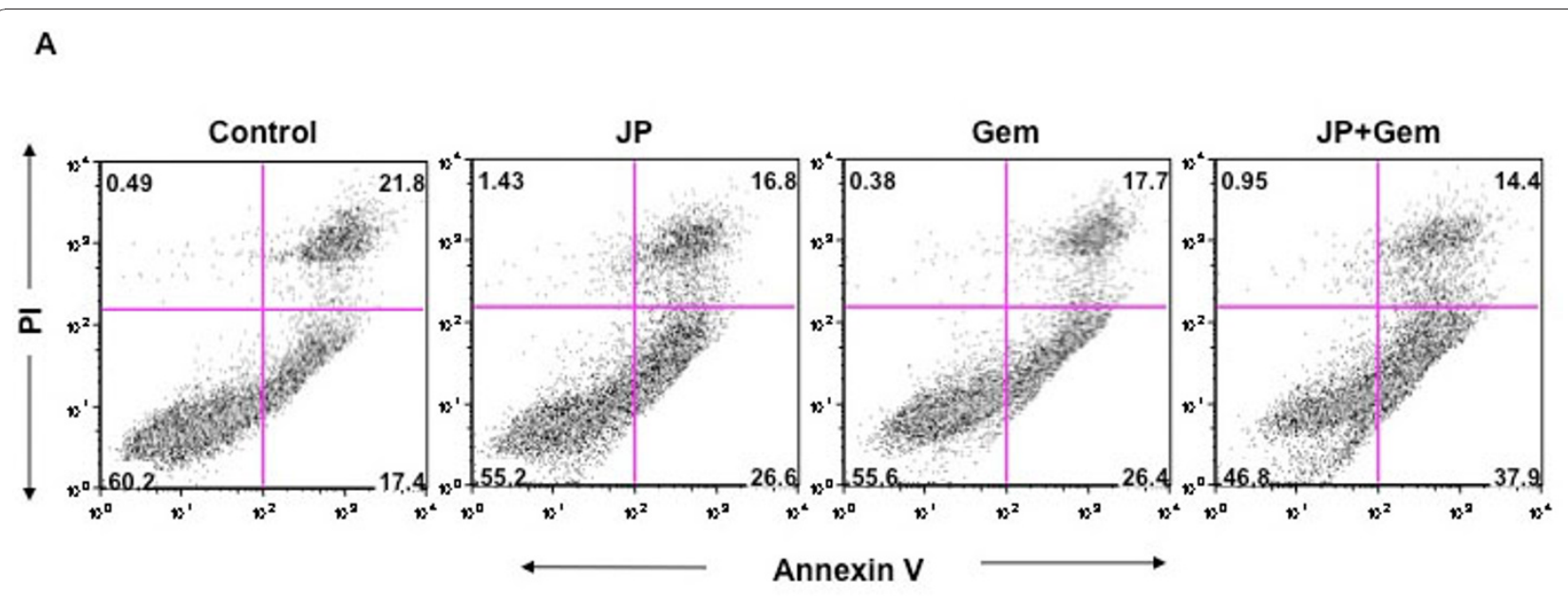

B

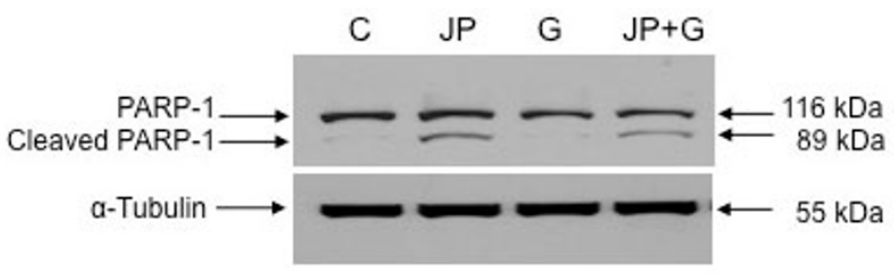

Figure 2 Effects of JP and Gem on PDAC cell apoptosis. AsPC-1 cells were treated with JP $(10 \mu \mathrm{M})$ and Gem (10 $\mu \mathrm{M})$ either alone or in combination. (A) The early apoptotic cells (lower right quadrant) were measured by flow cytometry after staining with FITC-conjugated annexin $\checkmark$ and propidium iodide. The percentage of cells in each quadrant is indicated within the quadrant. (B) PARP-1 cleavage was measured by Western blotting. The total cell lysate was subjected to SDS-PAGE and immunoblotted with PARP-1 antibody, which recognizes full-length (116 $\mathrm{kDa})$ and cleaved (89 kDa) PARP-1 protein. Expression of $\alpha$-tubulin $(55 \mathrm{kDa})$ was analyzed as loading control on a separate gel. Data are representative of two independent experiments with similar results.

combination treatment effects of a novel Smac mimetic, JP1201, in combination with the deoxycytidine analogue gemcitabine and the cell-mitosis inhibitor docetaxel in experimental pancreatic cancer.

Human PDAC cells lines have been shown to display marked heterogeneity towards Gem [29]. A similar heterogeneity regarding Gem sensitivity was seen in our four lines tested. Nevertheless, we observed that JP inhibited the proliferation of all four PDAC cell lines, and that the combination of JP + Gem had additive effects. Antitumor activity of Smac mimetics is mediated through induction of apoptosis. We therefore explored if proliferation inhibition of PDAC cells after combination therapy is in part due to induction in apoptosis. Detection of early apoptotic cells by annexin V/PI staining demonstrated that JP and Gem moderately induced apoptosis, and JP + Gem had an additive effect. Smac mimetic-induced apoptosis involves caspase activation that cleaves PARP-1, a DNA repair enzyme, to produce $89 \mathrm{kDa}$ or $24 \mathrm{kDa}$ cleavage product. We observed a dramatic increase in the $89 \mathrm{kDa} \mathrm{C}$ - terminus cleavage product of PARP-1 after JP treatment indicating the involvement of caspases in JP-induced apoptosis. While Gem treatment for 12 hours caused an increase in annexin V positive cells, no PARP-1 cleavage was detected after 24 hours of Gem treatment; this finding is likely related to the fact that 24 hours incubation may not be enough to cause detectable levels of PARP-1 cleavage. Based on in vitro additive anti-proliferative and proapoptotic effects of JP and Gem together, we examined effects of these agents on in vivo animal survival and observed that the JP + Gem combination significantly increases the animal survival compared with controls or monotherapy. Our findings corroborate a recently published report [23] that the Smac mimetic JP1201 enhances chemotherapy response of Gem in PDAC cell lines; accordingly, the JP-mediated increase in antiproliferative response after Gem was greatest in Panc-1 cells followed by MIA PaCa-2, BxPC-3 and AsPC-1 cells. Correspondingly, a $30 \%$ reduction in tumor weight was observed in our orthotopic Panc-1 tumor experiment compared to a 

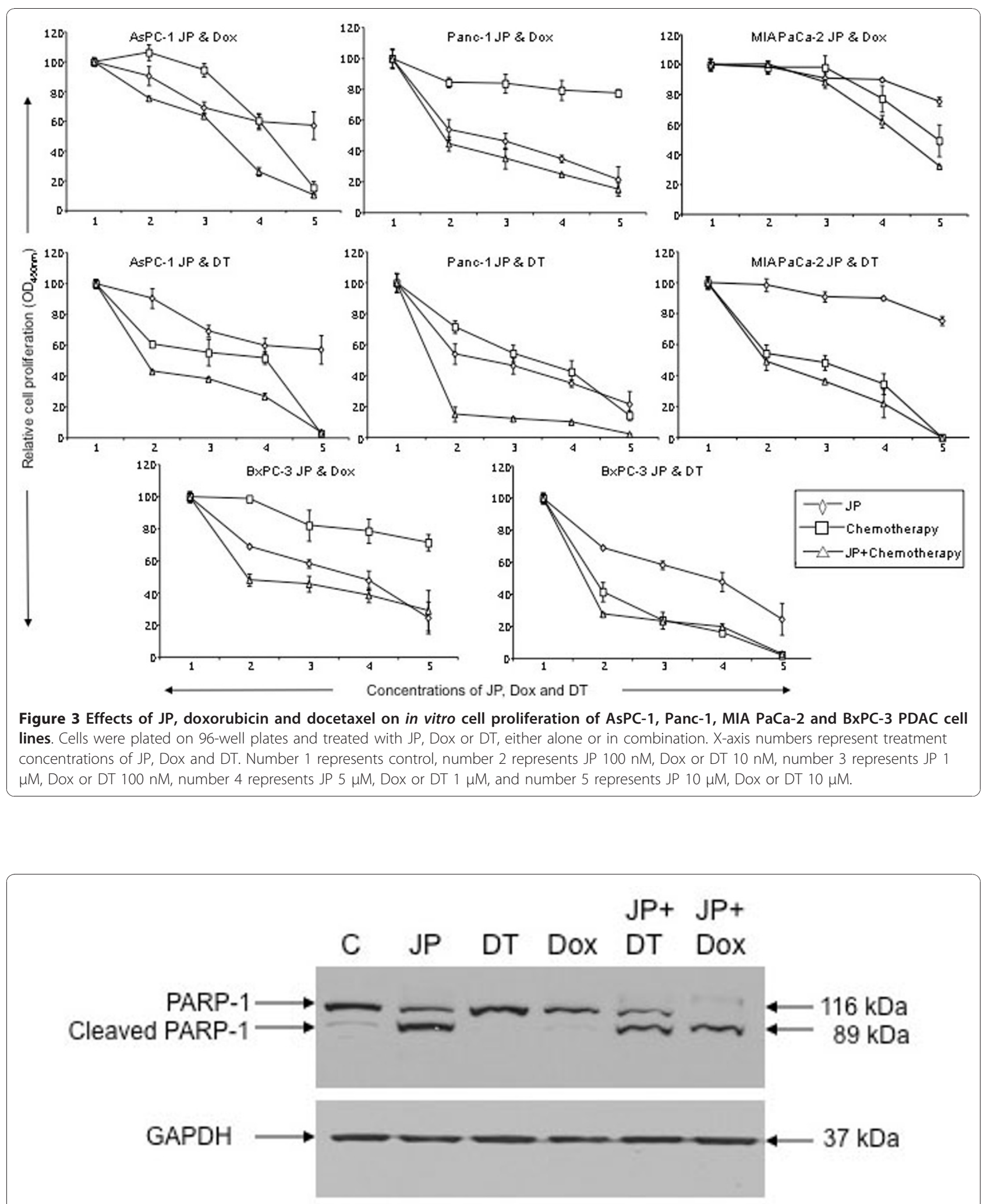

Figure 4 Effects of JP, Dox and DT on PAPR-1 cleavage. AsPC-1 cells were treated with JP $(10 \mu \mathrm{M})$, Dox $(10 \mu \mathrm{M})$ or DT (10 $\mu \mathrm{M})$, either alone or in combination. PARP-1 cleavage was measured by Western blotting. The total cell lysate was subjected to SDS-PAGE and immunoblotted with PARP-1 antibody, which recognizes full-length (116 kDa) and cleaved (89 kDa) PARP-1 protein. Expression of GAPDH (37 kDa) was analyzed as loading control on a separate gel. Data are representative of two independent experiments with similar results. 


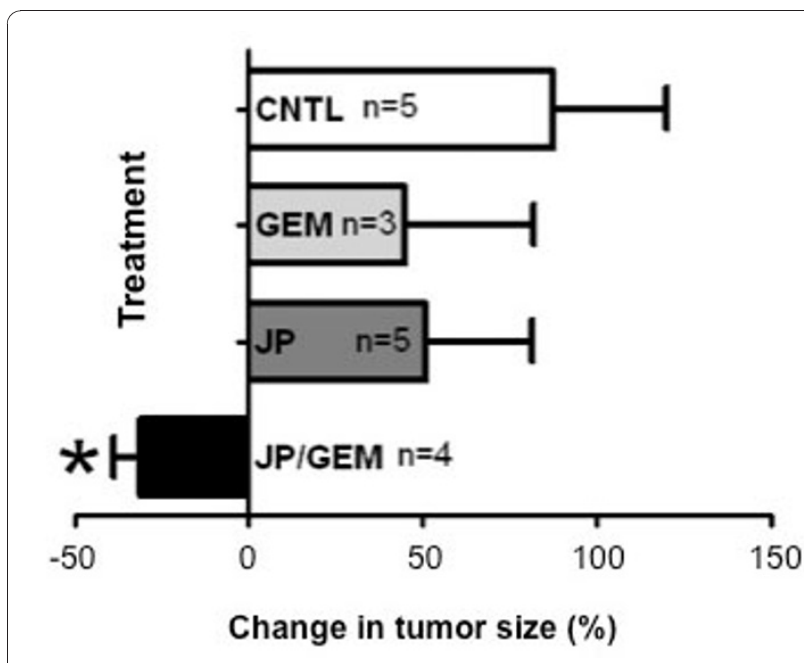

Figure 5 Effects of JP and Gem on animal tumor burden. Panc1 cells $\left(1 \times 10^{6}\right)$ were injected orthotopically in SCID mice. Eight weeks after tumor cell injection mice were randomized and treated with PBS (control), JP, Gem and JP + Gem. Three mice in each group were sacrificed at 24 hours of therapy, with a mean tumor weight of $0.594 \pm 0.08 \mathrm{~g}$. The remaining mice were sacrificed after 2 weeks. Symbol * represents $p<0.05$ verses control (CNTL).

$50 \%$ reduction in orthotopic MIA $\mathrm{PaCa}-2$ tumors in the previous study [23]. In addition, a significant improvement in animal survival was observed with JP + Gem treatment in AsPC-1 xenografts compared with JP or Gem alone similar to the previous study [23]. Of note, the lack of a significant reduction in tumor growth (Figure 5) by Gem alone in the present study is likely merely a result of the small number of animals in that tumor growth experiment, and does not pose a conflict with the significant improvement in animal survival seen after the same treatment (Figure 6A). Altogether, our results can thus support a more generalizable phenomenon in this context, as JP combination benefits have been obtained in four PDAC cell lines, and with other cytotoxic agents beyond gemcitabine.

Smac mimetics have been shown to enhance antitumor effects of several agents including cisplatin [30] and TRAIL [23,31] in different cancer types. Docetaxel is a clinically well established anti-mitotic chemotherapy treatment for several cancers including breast, ovarian and non-small cell lung cancer [32]. We explored the combination treatment effects of JP with other chemotherapy agents such as doxorubicin and docetaxel in experimental pancreatic cancer. In vitro studies showed that JP significantly enhanced antiproliferative effects of Dox and DT in all four PDAC cell lines tested. In addition JP and DT combination had significant enhanced effect on tumor regression and animal survival in pancreatic cancer xenografts. These results indicate that a potential clinical benefit to Smac-mimetic combination

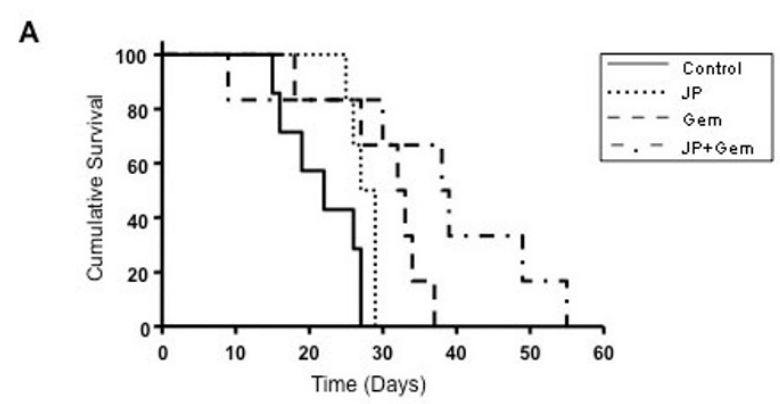

B

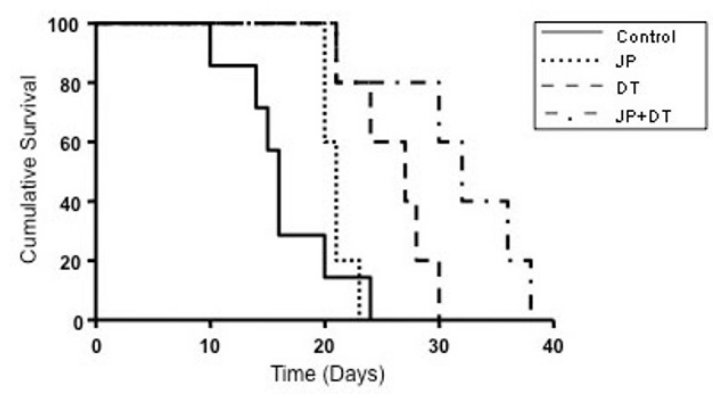

Figure 6 Effects of JP, Gem and DT, either alone or in combination on animal survival. AsPC-1 cells $\left(0.75 \times 10^{6}\right)$ were injected intraperitoneally in SCID mice and treatment started after 12 days. (A) Mice were treated with PBS (control), JP, Gem and $J P+G e m$ for 14 days. The curve represents the survival time from the beginning of therapy. The $p$ values for survival differences after Gem and JP + Gem versus control are 0.02 and 0.01 , respectively; JP + Gem versus Gem: $p=0.06$; JP + Gem versus JP: $p=0.02$. (B) Mice were treated with PBS (control), JP, DT and JP + DT for 14 days. The curve represents the survival time from the beginning of therapy. The $p$ values for survival differences after DT or JP + DT treatment versus control were 0.006; JP + Gem versus Gem: $p=0.05 ; \mathrm{JP}+$ Gem versus JP: $\mathrm{p}=0.04$.

therapies does not appear to be chemotherapeutic agent specific, and that such approach may carry a wide range of indications.

Small molecule Smac mimetics have been shown to be particularly advantageous in overcoming chemotherapy resistance when resistance occurs through modulation of the NFkB-IAP pathway. Since several pancreatic cancer cell lines and tumors have been shown to overexpress IAPs (16-18), treatment of PDAC with JP in combination with other chemotherapeutic agents shows specific promise for becoming effective for this disease. Our present study supports this notion through preliminary, preclinical evidence. The potential to render traditionally non-effective agents more effective for clinical PDAC therapy is particularly intriguing in this context.

\section{Conclusions}

Chemotherapy-induced apoptosis of PDAC can be enhanced through JP1201, a Smac mimetic. The resulting combination improves apoptotic response, antiproliferative 
effects, local tumor control, and animal survival. This strategy shows promise for future clinical evaluation.

\author{
Abbreviations \\ PDAC: pancreatic ductal adenocarcinoma; Gem or G: gemcitabine; DT: \\ docetaxel; PARP-1: poly (ADP-ribose) polymerase-1; WST-1: 4-[3-(4- \\ iodophenyl)-2-(4-nitrophenyl)-2H-5-tetrazolio]-1,3-benzene disulfonate; EC: \\ endothelial cell.
}

\section{Acknowledgements}

The authors thank Dr. Lai Wang for provision of JP1201, advice and technical support, and members of the Brekken and Schwarz labs for support and thoughtful discussion. This work was supported in part by the Effie Marie Cain Scholarship in Angiogenesis Research (to R. Brekken).

\section{Author details}

${ }^{1}$ Division of Surgical Oncology, Department of Surgery, The University of Texas Southwestern Medical Center Dallas, TX 75390, USA. ${ }^{2}$ Department of Pediatrics, The University of Texas Southwestern Medical Center Dallas, TX 75390. ${ }^{3}$ Hamon Center for Therapeutic Oncology Research, Simmons Comprehensive Cancer Center, The University of Texas Southwestern Medical Center Dallas, TX 75390. ${ }^{4}$ Department of Pharmacology The University of Texas Southwestern Medical Center Dallas, TX 75390.

\section{Authors' contributions}

NA was involved in the design of the study, execution of the experiments, data analysis and drafting the manuscript. AK and JET performed the orthotopic tumor growth studies. MAS participated in the animal survival studies. RAB contributed to the coordination of the study and manuscript preparation. RES conceived of the study, and was involved in the planning and design of the study, data analysis and drafting of the manuscript. All the authors read and approved the manuscript.

\section{Competing interests}

The authors declare that they have no competing interests.

Received: 16 April 2010 Accepted: 12 January 2011

Published: 12 January 2011

\section{References}

1. Jemal A, Siegel R, Ward E, Hao Y, Xu J, Thun MJ: Cancer statistics, 2009. CA Cancer J Clin 2009, 59(4):225-249.

2. Warshaw AL, Fernandez-del Castillo C: Pancreatic carcinoma. N Engl J Med 1992, 326(7):455-465.

3. Duffy JP, Eibl G, Reber HA, Hines OJ: Influence of hypoxia and neoangiogenesis on the growth of pancreatic cancer. Mol Cancer 2003, $2: 12$.

4. Wilkowski R, Thoma M, Bruns C, Duhmke E, Heinemann V: Combined chemoradiotherapy for isolated local recurrence after primary resection of pancreatic cancer. JOP 2006, 7(1):34-40.

5. Burris HA, Moore MJ, Andersen J, Green MR, Rothenberg ML, Modiano MR, Cripps MC, Portenoy RK, Storniolo AM, Tarassoff P, et al: Improvements in survival and clinical benefit with gemcitabine as first-line therapy for patients with advanced pancreas cancer: a randomized trial. J Clin Oncol 1997, 15(6):2403-2413.

6. Correale P, Messinese S, Marsili S, Ceciarini F, Pozzessere D, Petrioli R, Sabatino M, Cerretani D, Pellegrini M, Di Palma T, et al: A novel biweekly pancreatic cancer treatment schedule with gemcitabine, 5-fluorouracil and folinic acid. Br J Cancer 2003, 89(2):239-242.

7. Duffy A, Kortmansky J, Schwartz GK, Capanu M, Puleio S, Minsky B, Saltz L, Kelsen DP, O'Reilly EM: A phase I study of erlotinib in combination with gemcitabine and radiation in locally advanced, non-operable pancreatic adenocarcinoma. Ann Oncol 2008, 19(1):86-91.

8. Heinemann V, Quietzsch D, Gieseler F, Gonnermann M, Schonekas H, Rost A, Neuhaus H, Haag C, Clemens M, Heinrich B, et al: Randomized phase III trial of gemcitabine plus cisplatin compared with gemcitabine alone in advanced pancreatic cancer. J Clin Oncol 2006, 24(24):3946-3952.

9. Louvet C, Labianca R, Hammel P, Lledo G, Zampino MG, Andre T, Zaniboni A, Ducreux M, Aitini E, Taieb J, et al: Gemcitabine in combination with oxaliplatin compared with gemcitabine alone in locally advanced or metastatic pancreatic cancer: results of a GERCOR and GISCAD phase III trial. J Clin Oncol 2005, 23(15):3509-3516.

10. Lutz MP, Van Cutsem E, Wagener T, Van Laethem JL, Vanhoefer U, Wils JA, Gamelin E, Koehne CH, Arnaud JP, Mitry E, et al: Docetaxel plus gemcitabine or docetaxel plus cisplatin in advanced pancreatic carcinoma: randomized phase II study 40984 of the European Organisation for Research and Treatment of Cancer Gastrointestinal Group. J Clin Oncol 2005, 23(36):9250-9256.

11. Rocha Lima CM, Green MR, Rotche R, Miller WH Jr, Jeffrey GM, Cisar LA, Morganti A, Orlando N, Gruia G, Miller LL: Irinotecan plus gemcitabine results in no survival advantage compared with gemcitabine monotherapy in patients with locally advanced or metastatic pancreatic cancer despite increased tumor response rate. J Clin Oncol 2004, 22(18):3776-3783.

12. Van Cutsem $E$, van de Velde $H$, Karasek $P$, Oettle $H$, Vervenne WL Szawlowski A, Schoffski P, Post S, Verslype C, Neumann H, et al: Phase III trial of gemcitabine plus tipifarnib compared with gemcitabine plus placebo in advanced pancreatic cancer. J Clin Oncol 2004, 22(8):1430-1438.

13. Schmitt CA: Senescence, apoptosis and therapy-cutting the lifelines of cancer. Nat Rev Cancer 2003, 3(4):286-295

14. Gordon GJ, Appasani K, Parcells JP, Mukhopadhyay NK, Jaklitsch MT, Richards WG, Sugarbaker DJ, Bueno R: Inhibitor of apoptosis protein-1 promotes tumor cell survival in mesothelioma. Carcinogenesis 2002, 23(6):1017-1024

15. Nachmias B, Ashhab Y, Ben-Yehuda D: The inhibitor of apoptosis protein family (IAPs): an emerging therapeutic target in cancer. Semin Cancer Biol 2004, 14(4):231-243.

16. Karikari CA, Roy I, Tryggestad E, Feldmann G, Pinilla C, Welsh K, Reed JC, Armour EP, Wong J, Herman J, et al: Targeting the apoptotic machinery in pancreatic cancers using small-molecule antagonists of the X-linked inhibitor of apoptosis protein. Mol Cancer Ther 2007, 6(3):957-966.

17. Lopes RB, Gangeswaran R, McNeish IA, Wang Y, Lemoine NR: Expression of the IAP protein family is dysregulated in pancreatic cancer cells and is important for resistance to chemotherapy. Int J Cancer 2007, 120(11):2344-2352

18. Shrikhande SV, Kleeff J, Kayed H, Keleg S, Reiser C, Giese T, Buchler MW, Esposito I, Friess H: Silencing of X-linked inhibitor of apoptosis (XIAP) decreases gemcitabine resistance of pancreatic cancer cells. Anticancer Res 2006, 26(5A):3265-3273.

19. Chai J, Du C, Wu JW, Kyin S, Wang X, Shi Y: Structural and biochemical basis of apoptotic activation by Smac/DIABLO. Nature 2000, 406(6798):855-862.

20. Du C, Fang M, Li Y, Li L, Wang X: Smac, a mitochondrial protein that promotes cytochrome c-dependent caspase activation by eliminating IAP inhibition. Cell 2000, 102(1):33-42.

21. Li L, Thomas RM, Suzuki H, De Brabander JK, Wang X, Harran PG: A small molecule Smac mimic potentiates TRAIL- and TNFalpha-mediated cell death. Science 2004, 305(5689):1471-1474.

22. Vogler M, Walczak H, Stadel D, Haas TL, Genze F, Jovanovic M, Bhanot U, Hasel C, Moller P, Gschwend JE, et al: Small molecule XIAP inhibitors enhance TRAIL-induced apoptosis and antitumor activity in preclinical models of pancreatic carcinoma. Cancer Res 2009, 69(6):2425-2434.

23. Dineen SP, Roland CL, Greer R, Carbon JG, Toombs JE, Gupta P, Bardeesy N, Sun H, Williams N, Minna JD, et al: Smac mimetic increases chemotherapy response and improves survival in mice with pancreatic cancer. Cancer Res 70(7):2852-2861.

24. Awasthi N, Schwarz MA, Verma V, Cappiello C, Schwarz RE: Endothelial monocyte activating polypeptide II interferes with VEGF-induced proangiogenic signaling. Lab Invest 2009, 89(1):38-46.

25. Schwarz RE, McCarty TM, Peralta EA, Diamond DJ, Ellenhorn JD: An orthotopic in vivo model of human pancreatic cancer. Surgery 1999 126(3):562-567.

26. Lowe SW, Lin AW: Apoptosis in cancer. Carcinogenesis 2000, 21(3):485-495.

27. Oltersdorf T, Elmore SW, Shoemaker AR, Armstrong RC, Augeri DJ, Belli BA, Bruncko M, Deckwerth TL, Dinges J, Hajduk PJ, et al: An inhibitor of Bcl-2 family proteins induces regression of solid tumours. Nature 2005 435(7042):677-681

28. LaCasse EC, Mahoney DJ, Cheung HH, Plenchette S, Baird S, Korneluk RG: IAP-targeted therapies for cancer. Oncogene 2008, 27(48):6252-6275. 
29. Akada M, Crnogorac-Jurcevic T, Lattimore S, Mahon P, Lopes R,

Sunamura $M$, Matsuno $S$, Lemoine NR: Intrinsic chemoresistance to gemcitabine is associated with decreased expression of BNIP3 in pancreatic cancer. Clin Cancer Res 2005, 11(8):3094-3101.

30. Checinska A, Hoogeland BS, Rodriguez JA, Giaccone G, Kruyt FA: Role of XIAP in inhibiting cisplatin-induced caspase activation in non-small cell lung cancer cells: a small molecule Smac mimic sensitizes for chemotherapy-induced apoptosis by enhancing caspase-3 activation. Exp Cell Res 2007, 313(6):1215-1224.

31. Petrucci E, Pasquini L, Petronelli A, Saulle E, Mariani G, Riccioni R, Biffoni M, Ferretti G, Benedetti-Panici P, Cognetti F, et al: A small molecule Smac mimic potentiates TRAIL-mediated cell death of ovarian cancer cells. Gynecol Oncol 2007, 105(2):481-492.

32. Lyseng-Williamson KA, Fenton C: Docetaxel: a review of its use in metastatic breast cancer. Drugs 2005, 65(17):2513-2531.

\section{Pre-publication history}

The pre-publication history for this paper can be accessed here: http://www.biomedcentral.com/1471-2407/11/15/prepub

doi:10.1186/1471-2407-11-15

Cite this article as: Awasthi et al: Smac mimetic-derived augmentation of chemotherapeutic response in experimental pancreatic cancer. $B M C$ Cancer 2011 11:15.

\section{Submit your next manuscript to BioMed Central} and take full advantage of:

- Convenient online submission

- Thorough peer review

- No space constraints or color figure charges

- Immediate publication on acceptance

- Inclusion in PubMed, CAS, Scopus and Google Scholar

- Research which is freely available for redistribution

Submit your manuscript at www.biomedcentral.com/submit 